\title{
PENENTUAN HARGA POKOK PRODUKSI, KONTRIBUSI PENDAPATAN \\ USAHA DAN PEMASARAN BREM DI DESA GEBANG KECAMATAN \\ NGUNTORONADI \\ KABUPATEN WONOGIRI PROPINSI JAWA TENGAH
}

\author{
Nyayu Neti Arianti ${ }^{1}$ \\ Sigit Budi Sudjalmo ${ }^{1}$ \\ Retnoningrum Ririn $\mathrm{P}^{2}$ \\ ${ }^{1}$ Staf Pengajar Jurusan Sosial Ekonomi Pertanian Fak. Pertanian UNIB \\ ${ }^{2}$ Alumni Jurusan Sosial Ekonomi Pertanian Fak. Pertanian UNIB
}

\section{RINGKASAN}

Penelitian ini bertujuan untuk : mengetahui : 1) Mengetahui besarnya harga pokok produksi pada industri rumah tangga brem di Desa Gebang, 2) Mengetahui besarnya kontribusi pendapatan usaha pengolahan brem terhadap penerimaan rumah tangga pengolah brem di desa Gebang, 3) Mengetahui bentuk saluran pemasaran dan marjin pemasaran brem di Desa Gebang. Penentuan lokasi penelitian dilakukan secara sengaja yaitu di Desa Gebang, penentuan responden dengan metode sensus dimana responden yang diambil sebanyak 20 orang pengolah brem. Sedangkan untuk lembaga pemasaran melalui penelusuran sebanyak 2 orang pedagang pengumpul desa (PPD), 2 orang pedagang antar kota $(P A K)$ dan 4 orang pedagang pengecer (PP). Data yang digunakan adalah data primer dan sekunder. Analisis yang digunakan adalah analisis penentuan harga pokok produksi,analisis kontribusi penerimaan dan analisis pemasaran. Dari hasil penelitian diketahui bahwa harga pokok produksi rata-rata pengolahan brem per periode produksi adalah $\mathrm{Rp} 14.731,77 \mathrm{per} \mathrm{kg}$, kontribusi pendapatan usaha pengolahan brem terhadap pendapatan rumah tangga adalah sebesar 32,28\% termasuk kategori tinggi. Sedangkan saluran pemasaran brem di Desa Gebang terdiri dari 3 saluran, yaitu: 1 pengolah menjual brem ke PPD, PPD menjual ke PAK, PAK menjual ke $P P$, PP menjual ke konsumen. 2) PAK menjual brem ke PPL. 3) PAK menjual brem ke PB di Yogyakarta. Marjin pemasaran yang diterima PPD adalah sebesar Rp 2.000,00 per kg, PAK sebesar Rp 3.000,00 dan PP sebesar Rp 5.000,00

\section{PENDAHULUAN}

Sebagai motor penggerak pembangunan pertanian, agroindustri diharapkan akan dapat memainkan peranan penting dalam kegiatan pembangunan daerah, pertumbuhan ekonomi maupun stabilitas nasional. Sejauh mana peranan agroindustri dalam mengurangi kemiskinan dan pengangguran, serta sejauh mana agroindustri mampu memperbaiki 
pendapatan masyarakat pedesaan tergantung pada faktor di dalam dan di luar agroindustri. Faktor dalam adalah sejauhmana agroindustri mampu memberikan respon terhadap tantangan yang dihadapi. Sedangkan faktor dari luar agroindustri dapat memberikan kesempatan dan kepastian kepada agroindustri untuk tumbuh dan berkembang (Ningsih, 2002).

Salah satu contoh produk baru yang lebih diterima konsumen adalah makanan yang disebut brem. Brem adalah makanan yang terbuat dari beras ketan putih. Melalui proses fermentasi, beras ketan putih yang sudah dimasak diolah menjadi brem. Brem ini rasanya manis, dan banyak mengandung vitamin B1(Ningsih, 2002).

Dengan mengolah beras ketan menjadi brem akan meningkatkan pendapatan pengolah brem. Salah satu aspek perencanaan produksi adalah penentuan harga pokok produksi pengolahan brem. Dengan penentuan harga pokok produksi yang tepat sangat menentukan besar kecilnya kerugian maupun keuntungan yang akan diterima pengolah brem yang akan berdampak pada pendapatan pengolah brem dan kontribusinya bagi .rumah tangga pengolah brem.

Dalam penyaluran produk pertanian diperlukan adanya lembaga-lembaga pemasaran, masing- masing lembaga pemasaran melakukan fungsi secara berbeda-beda, adanya perbedaan dalam penyaluran dan perlakuan dari lembaga dalam saluran pemasaran, menyebabkan timbulnya perbedaan harga. Perbedaan harga ini menimbulkan marjin pemasaran yakni selisih antara harga yang dibayarkan konsumen dengan harga yang diterima produsen (Yuliana,1998).

Penelitian ini dimaksudkan untuk Berapa besar harga pokok produksi, dan seberapa besar kontribusi pendapatan usaha pengolahan brem terhadap pendapatan rumah tangga pengolahan brem di Desa Gebang.

\section{METODE PENELITIAN}


Penentuan lokasi penelitian ini dilakukan secara sengaja (purposive) yaitu di Desa Gebang Kecamatan Nguntoronadi Kabupaten Wonogiri, dengan pertimbangan bahwa lokasi ini merupakan sentra produksi brem di Kabupaten Wonogiri

Populasi dalam penelitian ini adalah industri rumah tangga pengolah brem dan lembaga pemasaran di Desa Gebang Kecamatan Nguntoronadi Kabupaten Wonogiri. Penentuan responden dengan metode sensus, dimana melibatkan seluruh populasi sebagai responden (Nazir,1998). Ini berarti seluruh pengolah brem di Desa Gebang dijadikan responden, yaitu sebanyak 20 orang. Lembaga pemasaran diperoleh melalui penelusuran, yang dijadikan responden adalah orang yang melakukan pembelian brem dari desa Gebang terdiri dari 2 orang Pedagang Pengumpul Desa (PPD) yang ada di Desa Gebang,2 Pedagang Antar Kota (PAK) dan 4 orang Padagang Pengecer (PP) yang ada di pasar Wonogiri.

Metode pengolahan data yang digunakan dalam perhitunagan harga pokok produksi adalah persamaan matematis dari Garrison (2002) :

Jumlah Biaya Produksi (Rp/pp)

Harga Pokok produksi $=$ Jumlah Satuan produk $(\mathrm{Kg} / \mathrm{pp})$

Untuk mengetahui pendapatan usaha pengolahan brem digunakan persamaan matematis dari Soekartawi (1995) :

$\mathrm{Pd}=\mathrm{TR}-\mathrm{TC}$

Dimana :

$$
\begin{aligned}
& \mathrm{TR}=\mathrm{Y} . \mathrm{P} \\
& \mathrm{TC}=\mathrm{FC}+\mathrm{VC}
\end{aligned}
$$

Keterangan :

$\mathrm{Pd} \quad=$ Pendapatan usaha pengolahan brem $(\mathrm{Rp} /$ periode produksi $(\mathrm{PP}))$

TR $=$ Total penerimaan usaha pengolahan brem $(\mathrm{Rp} / \mathrm{PP})$ 
$\mathrm{TC}=$ Total biaya pengolahan brem $(\mathrm{Rp} / \mathrm{PP})$

$\mathrm{Y} \quad=$ Jumlah produksi $(\mathrm{Kg} / \mathrm{PP})$

Py $\quad=$ harga $(\mathrm{Rp} / \mathrm{kg})$

$\mathrm{FC}=$ Biaya tetap $(\mathrm{Rp} / \mathrm{PP})$

$\mathrm{VC}=$ Biaya variabel $(\mathrm{Rp} / \mathrm{PP})$

Dari formulasi pendapatan diatas maka dapat dianalisis kontribusi penerimaan pengolah brem dengan rumus pendekatan sebagai berikut :

TR

$$
\mathrm{K}=\frac{}{\text { Pr total }} \times 100 \%
$$

Dimana :

$\mathrm{K}=$ Kontribusi penerimaan usaha pengolahan brem (persen)

TR = Penerimaan usaha pengolahan brem $(\mathrm{Rp} / \mathrm{bulan})$

Pr total = Total penerimaan rumah tangga usaha pengolahan brem + penerimaan dari kegiatan bidang usaha lainnya (Rp/bulan)

Untuk mengetahui bagaimana bentuk saluran pemasaran brem maka dianalisis secara diskriptif yaitu menggambarkan atau menjelaskan saluran pemasaran brem di daerah penelitian

Secara matematis persamaan marjin pemasaran dari Azzaino (1983) adalah :

$$
\begin{aligned}
& \mathrm{Mji}=\mathrm{Psi}-\mathrm{Pbi}, \text { atau } \\
& \mathrm{Mji}=\mathrm{Ci}+\pi \mathrm{i} \\
& \Pi \mathrm{i}=\mathrm{Mji}+\mathrm{Ci} \\
& \mathrm{Mj}=\sum_{i=1}^{i=n} \mathrm{Mji}
\end{aligned}
$$

Dimana :

Mji = Marjin pemasaran pada lembaga pemasaran ke-i

Psi = Harga jual lembaga pemasaran ke-i

Pbi = Harga beli lembaga pemasaran ke-i 
$\mathrm{Ci}=$ Biaya pemasaran lembaga ke- $\mathrm{i}$

$\Pi \mathrm{i}=$ Keuntungan lembaga pemasaran ke- $\mathrm{i}$

$\mathrm{Mj}=$ Total Marjin Pemasaran

\section{HASIL DAN PEMBAHASAN}

\section{Harga Pokok Produksi}

Penentuan harga pokok produksi brem dilakukan dengan cara membagi biaya produksi yang dikeluarkan dengan jumlah produksi yang dihasilkan oleh pengolah brem. Perhitungan harga pokok produksi ini bertujuan untuk melihat perbandingan antara harga pokok dan harga jual. Untuk lebih jelasnya dapat dilihat pada Tabel 6.

Tabel 6. Rata-rata Harga Pokok Produksi Usaha Pengolahan Brem di Desa Gebang

\begin{tabular}{lcc}
\hline Uraian & Jumlah (per PP) & Jumlah(per Bln) \\
\hline Biaya Produksi (Rp) & $398.972,01$ & $1.595 .888,05$ \\
Produksi (Kg) & 27,10 & 108,40 \\
\hline Harga Pokok Produksi (Rp/Kg) & $14.731,77$ & $14.731,77$
\end{tabular}

Sumber : Data Primer Diolah,2006

\section{Produksi, Penerimaan dan Pendapatan}

Penerimaan merupakan perkalian antara jumlah produksi brem dengan harga jual brem yang berlaku pada saat penelitian. Besarnya produksi, penerimaan dan pendapatan pengolah brem dapat dilihat pada Tabel 3

Tabel 3. Rata-rata Penerimaan dan Pendapatan Brem Pada Usaha Pengolahan Brem di Desa Gebang

\begin{tabular}{llrr}
\hline No & Uraian & \multicolumn{2}{c}{ Jumlah } \\
\cline { 3 - 4 } & & $($ per PP) & \multicolumn{1}{c}{ (per Bln) } \\
\hline 1 & Penerimaan & & \\
& (Rp) & & \\
& - Brem & $406.500,00$ & $1.626 .000,00$ \\
& - Ampas & $81.300,00$ & $325.200,00$ \\
& Total & $487.800,00$ & $1.951 .200,00$ \\
& Penerimaan & & \\
2 & Biaya Produksi & $398.972,01$ & $1.595 .888,05$ \\
& Brem & & \\
& Biaya Ampas & - & - \\
& Total Biaya & $398.972,01$ & $1.595 .888,05$ \\
& Produksi & & \\
& Pendapatan & & $30.111,95$ \\
\hline
\end{tabular}




\begin{tabular}{lll}
\hline - Ampas & $81.300,00$ & $325.200,00$ \\
Total & $88.827,99$ & $355.311,95$ \\
Pendapatan & & \\
\hline
\end{tabular}

Sumber: Data primer Diolah,2006

Pendapatan adalah penerimaan bersih yang diterima oleh pengolah brem dalam usaha pengolahan brem. Pendapatan brem diperoleh dari penjualan brem dan ampas brem. Ampas brem dimanfaatkan warga untuk makanan ternak sebagai pemacu penggemukan sapi dengan harga jualnya Rp. 2000 per kg. Dari Tabel diatas dapat dilihat bahwa ratarata pendapatan yang diperoleh pengolah brem per PP adalah $\mathrm{Rp} 88.827,99$ atau Rp.355.311,95 per bulan (Lampiran 15).

Tabel diatas menunjukkan bahwa pendapatan dari usaha pengolahan brem sangat kecil, hal ini disebabkan karena harga jual brem ditingkat produsen tidak sebanding dengan biaya produksi. Kecilnya harga jual yang ditawarkan oleh produsen disebabkan karena proses pembuatan brem ini masih sangat sederhana dan bersifat tradisional sehingga kualitas brem yang dihasilkan masih sangat rendahPenerimaan merupakan perkalian antara jumlah produksi brem dengan harga jual brem yang berlaku pada saat penelitian. Besarnya produksi, penerimaan dan pendapatan pengolah brem dapat dilihat pada Tabel 3

Tabel 3. Rata-rata Penerimaan dan Pendapatan Brem Pada Usaha Pengolahan Brem di Desa Gebang

\begin{tabular}{|c|c|c|c|}
\hline \multirow[t]{2}{*}{ No } & \multirow[t]{2}{*}{ Uraian } & \multicolumn{2}{|c|}{ Jumlah } \\
\hline & & (per PP) & (per Bln) \\
\hline \multirow[t]{5}{*}{1} & $\begin{array}{l}\text { Penerimaan } \\
\text { (Rp) }\end{array}$ & & \\
\hline & - Brem & $406.500,00$ & $1.626 .000,00$ \\
\hline & - Ampas & $81.300,00$ & $325.200,00$ \\
\hline & Total & $487.800,00$ & $1.951 .200,00$ \\
\hline & Penerimaan & & \\
\hline \multirow[t]{3}{*}{2} & $\begin{array}{l}\text { Biaya Produksi } \\
\text { Brem }\end{array}$ & $398.972,01$ & $1.595 .888,05$ \\
\hline & Biaya Ampas & - & - \\
\hline & $\begin{array}{ll}\text { Total } & \text { Biaya } \\
\text { Produksi } & \end{array}$ & $398.972,01$ & $1.595 .888,05$ \\
\hline \multirow[t]{4}{*}{3} & Pendapatan & & \\
\hline & - Brem & $7.527,99$ & $30.111,95$ \\
\hline & - Ampas & $81.300,00$ & $325.200,00$ \\
\hline & $\begin{array}{l}\text { Total } \\
\text { Pendapatan }\end{array}$ & $88.827,99$ & $355.311,95$ \\
\hline
\end{tabular}

Sumber: Data primer Diolah,2006 
Pendapatan adalah penerimaan bersih yang diterima oleh pengolah brem dalam usaha pengolahan brem. Pendapatan brem diperoleh dari penjualan brem dan ampas brem. Ampas brem dimanfaatkan warga untuk makanan ternak sebagai pemacu penggemukan sapi dengan harga jualnya Rp. 2000 per kg. Dari Tabel diatas dapat dilihat bahwa ratarata pendapatan yang diperoleh pengolah brem per PP adalah Rp 88.827,99 atau Rp.355.311,95 per bulan (Lampiran 15).

Tabel diatas menunjukkan bahwa pendapatan dari usaha pengolahan brem sangat kecil, hal ini disebabkan karena harga jual brem ditingkat produsen tidak sebanding dengan biaya produksi. Kecilnya harga jual yang ditawarkan oleh produsen disebabkan karena proses pembuatan brem ini masih sangat sederhana dan bersifat tradisional sehingga kualitas brem yang dihasilkan masih sangat rendah.

\section{Kontribusi Pendapatan Terhadap Penerimaan Rumah Tangga}

Kontribusi penerimaan brem adalah besarnya sumbangan penerimaan dari hasil kegiatan pengolahan brem yang dibandingkan dengan penerimaan rumah tangga (dalam persen). Untuk lebih jelasnya rata-rata penerimaan rumah tangga pengolah brem dan kontribusi penerimaan brem dapat dilihat pada Tabel 4.

Tabel 4. Kontribusi Pendapatan Brem terhadap Pendapatan Rumah Tangga Pengolah Brem di Desa Gebang

\begin{tabular}{llcc}
\hline No & Sumber Pendapatan & Jumlah & Kontribusi (\%) \\
\hline 1 & Pendapatan Usaha Brem (Rp/Bln) & $355.311,95$ & 32,28 \\
& - Pendapatan Brem & $30.111,95$ & \\
& - Pendapatan Ampas Brem & $325.200,00$ & \\
2 & Pendapatan Kegiatan Bidang Usaha lain & & \\
& & & 28,05 \\
& - Pendapatan Pertanian(Rp/Bln) & $350.000,00$ & 39,67 \\
& - Pendapatan Luar Pertanian (Rp/Bln) & $440.000,00$ & \\
3 & Pendapatan RT(Rp/Bln) & $2.741 .200,00$ & \\
Sumber & Data Primer Diolah,2006
\end{tabular}


Dari Tabel 4 diatas dapat dilihat bahwa rata-rata pendapatan usaha pengolahan brem yang diterima pongolah adalah sebesar Rp 1.951.200,00 per bulan. Untuk rata-rata pendapatan dari sektor pertanian adalah sebesar Rp 350.000,00 per bulan, sedangkan untuk Pendapatan luar sektor pertanian adalah sebesar Rp 440.000,00 per bulan. Total pendapatan rumah tangga adalah sebesar Rp 2.741.200,00 per bulan. Pendapatan rumah tangga adalah jumlah keseluruhan pendapatan anggota keluarga yang terdiri dari usaha pengolahan brem dan dari kegiatan bidang usaha lain (Lampiran 18).

Tabel 4 menunjukkan bahwa kontribusi pendapatan usaha pengolahan brem terhadap pendapatan rumah tangga pengolah brem di Desa Gebang adalah sebesar 32,28 \% ini termasuk dalam klasifikasi yang rendah. Dengan klasifikasi yang rendah maka pengolah perlu mempertimbangkan lagi untuk tetap melakukan usaha pengolahan brem atau meningkatkan kualitas brem yang diolah agar dapat meningkatkan harga jual sehingga dapat meningkatkan pendapatan

\section{Pemasaran}

\subsubsection{Karakteristik Lembaga Pemasaran}

Lembaga pemasaran yang terlibat dalam pemasaran brem dari produsen sampai ke konsumen terdiri dari pedagang pengumpul desa (PPD), pedagang antar kota (PAK) dan pedagang pengecer (PP). Karakteristik lembaga pemasaran yang diamati dalam penelitian ini meliputi umur responden, lama pendidikan formal, dan lamanya berdagang. Untuk Lebih jelasnya rata-rata karakteristik lembaga pemasaran dapat dilihat padaTabel5

Tabel 5. Rata-rata Karakteristik Lembaga Pemasaran

\begin{tabular}{lllll}
\hline No & Uraian & PPD & PAK & PP \\
\hline \multirow{2}{*}{$\begin{array}{l}\text { Umur } \\
\text { (Tahun) }\end{array}$} & 38,00 & 36,00 & 40,75 \\
& $\begin{array}{l}\text { Pendidikan } \\
\text { (Tahun) }\end{array}$ & 12,00 & 10,50 & 7,50
\end{tabular}


$3 \quad \begin{aligned} & \text { Lama } \\ & \text { Berdagang } \\ & \text { (Tahun) }\end{aligned} \quad 10,50 \quad 8,50 \quad 19,25$

Dari Tabel 5 diketahui bahwa rata-rata umur pedagang pengumpul desa 38 tahun pedagang antar kota 36 tahun dan pedagang pengecer 40,75 tahun. Untuk lama pendidikan formal yang ditempuh pedagang berada pada kisaran 6-12 tahun, dengan rincian masingmasing, rata-rata pedagang pengumpul desa menempuh pendidikan formal selama 12 tahun, pedagang antar kota selama 10,5 tahun dan pedagang pengecer selama 7,5 tahun.

\subsubsection{Saluran Pemasaran}

Saluran pemasaran adalah seperangkat lembaga pemasaran yang melakukan kegiatan dalam menyalurkan brem dari produsen konsumen. Pemasaran brem didaerah penelitian dilakukan oleh 3 lembaga pemasaran, yaitu : pedagang pengumpul desa, pedagang antar kota dan pedagang pengecer.

Penelusuran pemasaran brem pada penelitian ini dimulai dari pengolah sebagai produsen sampai ke konsumen. Adapun saluran pemasaran di Desa.

\subsubsection{Analisis Marjin Pemasaran}

Marjin pemasaran brem adalah perbedaan harga yang dibayar oleh konsumen dengan harga yang diterima pengolah brem, terdiri dari biaya pemasaran dan keuntungan lembaga pemasaran. Dalam pemasaran brem dari produsen ke konsumen akan muncul biaya-biaya sebagai akibat perlakuan terhadap brem tersebut, misalnya biaya transportasi, biaya penyusutan alat, biaya tenaga kerja, biaya kemasan dan sebagainya. Dengan demikian biaya pemasaran adalah seluruh biaya yang dikeluarkan oleh lembaga pemasaran dalam memasarkan brem.

Dari hasil analisis data diperoleh harga jual yang berlaku pada produsen atau pengolah brem adalah sebesar Rp 15.000,00 per kg (60 \%) dari harga yang dibayarkan oleh konsumen akhir. Harga jual dari pengolah juga merupakan harga beli bagi PPD. PPD 
menjual brem dengan harga $\mathrm{Rp} 17.000,00$ per $\mathrm{kg}$ dengan demikian terdapat marjin pemasaran sebesar $\operatorname{Rp} 2.000,00$ atau $8 \%$ dari harga beli konsumen. Marjin ini didistribusikan untuk untuk biaya pemasaran sebesar Rp 263,42 per kg dan sisanya Rp 1.736,58 per kg atau 6,95\% dari harga beli konsumen merupakan keuntungan pemasaran. Selanjutnya PPD menjual brem kepada PAK dengan harga Rp 17.000,00 per kg dan PAK menjual brem kepada PP dengan harga Rp 20.000,00 sehingga terdapat marjin pemasaran sebesar Rp 3.000,00 per kg atau $12 \%$ dari harga beli konsumen. Marjin ini didistribusikan untuk biaya pemasaran sebesar Rp 312,91 per kg dan sisanya Rp 2.687,09 atau 10,74\% dari harga beli konsumen akhir merupakan keuntungan pemasaran. Biaya pemasaran pada PAK terdiri dari biaya tenaga kerja, biaya penyusutan alat dan biaya transportasi. Biaya transportasi pada PAK terdiri dari 2 biaya, yaitu biaya transportasi ke PPD dan PAK. Biaya transportasi ke PPD sebesar Rp 60,00 per kg, sedangkan biaya transportasi ke PP sebesar Rp 229,09 per kg. Besarnya biaya transportasi ke PP disebabkan karena jumlah brem yang dibawa sangat sedikit. Selanjutnya PP membeli brem dari PAK dengan harga Rp 20.000,00 dan menjualnya dengan harga $\mathrm{Rp} 25.000,00$ per $\mathrm{kg}$, dengan demikian terdapat marjin pemasaran sebesar Rp 5.000,00 per kg atau $20 \%$ dari harga beli konsumen. Marjin ini didistribusikan untuk biaya pemasaran sebesar Rp 2.279.55 dan sisanya Rp 2.720,45 atau 10,88 \% dari harga beli konsumen merupakan keuntungan pemasaran. Total keuntungan pemasaran untuk seluruh lembaga pemasaran adalah sebesar Rp 7.083,22 per kg.

Dari ketiga lembaga pemasaran brem di atas yang memperoleh marjin pemasaran terbesar adalah PP, sedangkan PPD memperoleh marjin pemasaran yang paling kecil. Perbedaan besarnya marjin pemasaran pada lembaga pemasaran dikarenakan adanya perbedaan biaya pemasaran yang dikeluarkan oleh lembaga pemasaran.

Keuntungan lembaga pemasaran adalah selisih antara marjin lembaga pemasaran dengan total biaya pemasaran yang dikeluarkan oleh lembaga pemasaran Keuntungan pemasaran 
terbesar terdapat pada PP. Sedangkan PPD mendapatkan keuntungan yang paling kecil. Besarnya keuntungan yang diperoleh lembaga pemasaran berbeda-beda, hal ini disebabkan adanya perbedaan marjin dan biaya pemasaran yang dikeluarkan lembaga pemasaran. Secara jelas marjin pemasaran dapat dilihat pada tabel 6.

Tabel 6. Marjin Pemasaran Brem di Desa Gebang Tabel 6. Marjin Pemasaran Brem di Desa Gebang

\begin{tabular}{lll}
\hline Uraian & Nilai $(\mathrm{Rp} / \mathrm{Kg})$ & Share $(\%)^{*}$ \\
\hline
\end{tabular}

\subsubsection{Pengolah Brem}

a. Harga jual

Pedagang Pengumpul Desa (PPD)

a. Harga beli

b. Biaya tenaga kerja

c. Biaya penyusutan alat

d. Biaya transportasi

e. Biaya kemasan

f. Total biaya $(b+c+d+e)$

g. Hargajual

h. Marjin (g-a)

i. Keuntungan (h-f)

\subsubsection{Pedagang Antar Kota (PAK)}

a. Harga beli

b. Biaya tenaga kerja

c. Biaya penyusutan alat

d. Transportasi

e. Total biaya $(b+c+d)$

f. Harga jual

g. Marjin (f-a)

h. Keuntungan (g-e)

\subsubsection{Pedagang Pengecer (PP)}
a. Harga beli
b. Biaya retribusi pasar
c. Biaya kemasan
d. Biaya penyusutan alat
e. Biaya sewa tempat
f. Total biaya $(b+c+d+e)$
g. Harga jual
h. Marjin ((g-a)
i. Keuntungan (h-f)

$\begin{array}{cr}15.000,00 & 60,00 \\ 15.000,00 & 60,00 \\ 63,95 & 0,26 \\ 12,07 & 0,05 \\ 60,73 & 0,24 \\ 126,66 & 0,51 \\ 263,42 & 1,05 \\ 17.000,00 & 68,00 \\ 2.000,00 & 8,00 \\ 1.736,58 & 6,95\end{array}$

$\begin{array}{cr}17.000,00 & 68,00 \\ 18,57 & 0,07 \\ 5,24 & 0,02 \\ 289,09 & 1,16 \\ 312,91 & 1,25 \\ 20.000,00 & 80,00 \\ 3.000,00 & 12,00 \\ 2.687,09 & 10,74\end{array}$

$\begin{array}{cr}20.000,00 & 80,00 \\ 613,13 & 2,45 \\ 90,94 & 0,36 \\ 42,68 & 0,17 \\ 1.532,81 & 6,13 \\ 2.279,55 & 9,12 \\ 25.000,00 & 100,00 \\ 5.000,00 & 20,00 \\ 2.720,45 & 10,88\end{array}$




\begin{tabular}{lr}
\hline j. Total biaya pemasaran & $2.916,78$ \\
k. Total keuntungan & $7.083,22$ \\
\hline l. Total Marjin & $10.000,00$ \\
\hline
\end{tabular}

Keterangan *) Persentase dari harga jual pengecer

Sumber : Data Primer Diolah,2006

\section{KESIMPULAN DAN SARAN}

\section{Kesimpulan}

Berdasarkan hasil penelitian dan pembahasan yang telah dilakukan, maka dapat ditarik kesimpulan sebagai berikut :

1. Harga pokok produksi pengolahan brem rata-rata per periode produksi adalah sebesar Rp 14.731,77 per kg.

2. Kontribusi pendapatan usaha pengolahan brem terhadap pendapatan Rumah Tangga (RT) adalah sebesar 32,28\% termasuk kategori rendah.

3. Bentuk saluran pemasaran brem di Desa Gebang terdiri dari 3 saluran pemasaran, yaitu saluran pemasaran I yaitu dari pengolah atau produsen menjual brem kepada PPD. PPD menjual brem ke PAK, kemudian brem dijual kepada PP di pasar wonogiri, PP menjual brem ke konsumen. Sedangkan saluran II. PAK menjual brem ke PPL. Saluran 3. PAK menjual brem ke PB di Yogyakarta. Marjin pemasaran yang diterima PPD adalah sebesar Rp 2.000,00 per kg, PAK sebesar Rp 3.000,00 dan PP sebesar Rp 5.000,00. Sedangkan total marjin pemasaran adalah $\operatorname{Rp} 10.000,00$.

\section{Saran}

1. Mengingat usaha pengolahan brem ini merupakan industri turun-temurun, maka kualitas SDM dan mutu produknya masih sederhana sehingga diperlukan bantuan dari pemerintah setempat untuk memberikan pelatihan untuk memproduksi brem dengan kualitas yang lebih baik dan kemasan khusus agar lebih lama daya 
tahannya. Dengan demikian pengolah brem akan memiliki nilai tawar yang tinggi kepada Pedagang Pengumpul Desa.

2. Hendaknya pemerintah memberikan bantuan berupa alat-alat produksi dengan teknologi yang lebih maju agar dapat meningkatkan kualitas brem yang dihasilkan.

\section{DAFTAR PUSTAKA}

Azzaino, Z. (1983). Pengantar Tataniaga Pertanian. Departemen ilmu-ilmu Sosial. Fakultas pertanian Institut Pertanian Bogor: Bogor.

Garrison. 2002. Akutansi Manajemen Jilid I. ITB: Bandung

Kotler, P. 1987. Manajemen Pemasaran Jilid I. Erlangga: Jakarta.

Nazir, M. 1998. Metodologi Penelitian. Ghalia Indonesia: Jakarta.

Ningsih. G. M. Analisis Nilai Tambah Agroindustri Brem (Studi Kasus di Kecamatan Mejayan Kabupaten Madiun). Tropika Volume 10. No.02, hal. 169-175, 2002. Jurusan Agribisnis. Fakultas Pertanian. UMM: Malang.

Soekartawi.1991. Agribisnis Teori dan Aplikasinya. Raja Grafindo Persada: Jakarta. 